\title{
A mathematical model for carbon fixation and nutrient removal by an algal photobioreactor
}

Ahmed M.D. Al Ketife ${ }^{1}$, Simon Judd ${ }^{2,3}$ and Hussein Znad ${ }^{1, *}$

${ }^{1}$ Department of Chemical Engineering, Curtin University; ${ }^{2}$ Gas Processing Center, Qatar University;

${ }^{3}$ Cranfield Water Science Institute, Cranfield University

*corresponding author

\section{Abstract}

A comprehensive mathematical modeling method for chlorella vulgaris $(C v)$ has been developed to assess the influence of nutrient concentration $(\mathrm{N}=28-207$ and $\mathrm{P}=6-8 \mathrm{mg}$ $\left.\mathrm{L}^{-1}\right)$ and UV irradiation intensity $(I=100-250 \mu \mathrm{E})$ at feed gas $\mathrm{CO}_{2}$ concentrations $\left(C_{c, g}\right)$ of 0.04-5\%. The model encompasses gas-to-liquid mass transfer, algal uptake of carbon dioxide $\left(C_{d}\right)$, nutrient removal efficiency (RE for $\mathrm{N}$ and $\mathrm{P}$ with reference to total nitrogen TN and total phosphorus TP), and the growth biokinetics of $C v$ with reference to the specific growth rate $\mu$ in $\mathrm{d}^{-1}$ ).

The model was validated using experimental data on the $C v$ species growth in an externally illuminated photobioreactor (PBR). The fitted parameters of the model were found to be in good agreement with experimental data obtained over the range of cultivation conditions explored. The mathematical model accurately reproduced the dynamic profiles of the algal biomass and nutrient (TN and TP) concentrations, and light attenuation at different input $C_{c, g}$ values. The proposed model may therefore be used for predicting algal growth and nutrient RE for this algal species, permitting both process optimization and scale-up.

Keywords:

Mathematical model, chlorella vulgaris, photobioreactor, light attenuation, Growth kinetics

\section{Symbols}

\begin{tabular}{ll}
$\underline{\text { Symbol }}$ & Description and units \\
\hline$C$ & Dissolved carbon concentration, $\mathrm{mg} \mathrm{L}^{-1}$ \\
$C_{s}$ & Saturated concentration of $\mathrm{CO}_{2}, \mathrm{mg} \mathrm{L}^{-1}$ \\
$D_{C}, D o$ & Diffusivity of of $\mathrm{CO}_{2}$, oxygen $\mathrm{m}^{2} \cdot \mathrm{s}^{-1}$ \\
$H_{C}, O$ & Henry constant for $\mathrm{O}_{2}$ or $\mathrm{CO}_{2}$ \\
$I$ & Light incident, $\mu \mathrm{E} \mathrm{m}^{-2} \mathrm{~s}^{-1}$ \\
$K$ & Light extinction coefficient, $\mathrm{g} \mathrm{m}^{-2}$ \\
$K_{c}$ & Chlorophyll-base light extinction coefficient of algae, $\mathrm{cm}^{2}$ (mg Chl-a). \\
$k_{C}, k_{O}$ & Mass transfer coefficient of $\mathrm{CO}_{2}$, oxygen, $\mathrm{d}^{-1}$ \\
$K_{d}$ & Biomass loss (death) rate, $\mathrm{d}^{-1}$ \\
$K_{i}$ & Carbon dissociation constant of species $i, \mathrm{~mol} \mathrm{~L}^{-1}$ \\
$K_{N}$ & half saturation constants for $\mathrm{N}$ \\
$K_{P}$ & half saturation constants for P \\
$K_{T C}$ & half saturation constant for total carbon \\
1 &
\end{tabular}




$\begin{array}{ll}L_{a v} & \text { Photosynthetically active radiation (PAR), } \mu \mathrm{E} \mathrm{m}^{-2} \mathrm{~s}^{-1} \\ K_{L} & \text { PAR half saturation constants, } \mu \mathrm{E} \mathrm{m}^{-2} \mathrm{~s}^{-1} \\ \mathrm{MW}_{\mathrm{i}} & \text { Molecular weight of species } i, \mathrm{~g} \mathrm{~mol}^{-1} \\ n & \text { Shape factor } \\ P & \text { Pressure, bar } \\ r & \text { Photobioreactor radius, } \mathrm{m} \\ R & \text { Universal gas constant, } \mathrm{L}^{3} \mathrm{bar}^{-1} \mathrm{k}^{-1} \mathrm{~mol}^{-1} \\ S_{i} & \text { Concentration of selected nutrient, } \mathrm{mg} \mathrm{L}^{-1} \\ T & \text { Temperature, }{ }^{\circ} \mathrm{K} \\ V & \text { Volume, } \mathrm{L} \\ X & \text { Biomass concentration, } \mathrm{g} \mathrm{L}^{-1} \\ y & \text { Mole fraction of } \mathrm{CO}_{2} \text { in gas phase } \\ Y_{C T O T} & \text { Yield coefficient for total carbon, }\left(\mathrm{g}_{\mathrm{c}} \mathrm{g}_{\mathrm{x}}{ }^{-1}\right) \\ Y_{i} & i \text { nutrient yield coefficient, }\left(\mathrm{g}_{\mathrm{i}} \mathrm{g}_{\text {biomass }}{ }^{-1}\right) \\ Y_{O 2} & \text { Oxygen yield coefficient, }\left(\mathrm{g}_{\mathrm{O} 2} \mathrm{~g}_{\text {biomass }}{ }^{-1}\right) \\ \text { Greek characters } & \\ \varepsilon & \text { Gas holdup volume, } \mathrm{L} \\ \gamma_{w, i} & \text { Half saturation constant for } i \text { nutrient } \gamma_{w, i} \\ \mu_{\text {max }} & \text { Maximum specific growth rate, } \mathrm{d}^{-1} \\ \theta & \text { Angle of incident light, }\left({ }^{\circ}\right) \\ \text { Subscripts } & \\ g & \text { Gas phase } \\ l & \text { Liquid phase } \\ \text { tot } & \text { Total concentration } \\ R & \text { Reactor } \\ \text { init } & \text { Initial value } \\ \text { atm } & \text { Atmospheric } \\ \text { feed } & \text { Feed } \\ & \end{array}$

\section{Introduction}

\subsection{Algal photobioreactor key system facets}

Environmental factors such as temperature, nutrient load and UV irradiation have a direct influence on biomass productivity in an algal photobioreactor (PBR). Effective and efficient microalgae cultivation relies on a number of fundamental system properties which include (i) distribution of UV dose throughout the biomass, (ii) enhanced $\mathrm{CO}_{2}$ mass transfer from the gas to liquid phase, (iii) enhanced $\mathrm{CO}_{2}$ assimilation by the algal biomass (largely achieved through (i)), and (iv) effective removal of $\mathrm{O}_{2}$ generated during the photosynthetic process which may otherwise inhibit the algal growth [1]. Carbon dioxide functions as the carbon source for most algae, with the assimilated carbon contributing about $50 \%$ of the algal biomass. The local carbon dioxide concentration at any point of a bubble column PBR should be above the minimum threshold to sustain photosynthesis to avoid carbon limitation [2].

As with all microorganisms, algal species demand various nutrients to support growth, of which nitrogen $(\mathrm{N})$ and phosphorus $(\mathrm{P})$ are the most important. The total $\mathrm{N}$ and $\mathrm{P}$ concentrations (TN and TP), relative to that of the algal biomass, may thus determine both algal growth and the corresponding nutrient depletion rate through their bioassimilation, as sustained by the UV light irradiation and the availability of dissolved $\mathrm{CO}_{2}$ [3]. Nitrogen starvation conditions have been extensively applied for maintaining 
metabolic fluxes to lipids [4] leading to protein synthesis, the excess photosynthesized carbon being stored as triacylglycerides or starch [5].

Light intensity and photoperiod cycle (i.e. the relative durations of the light and dark periods) are crucial factors in determining algal growth rate, especially for photoautotrophic cultures [6]. Inefficiencies arise when microalgae are exposed to light intensities above the saturation limits, as a result of photo-inhibition or overheating. Against this, at high algal cell densities commensurately higher light intensities are required to ensure light penetration through the bulk of the culture [7].

Microalgal PBR processes thus present a number of challenges for control and optimization. Mathematical models are thus needed which are capable of quantifying the impact of practical system parameters such as bioreactor configuration, $\mathrm{CO}_{2}$ mass transfer, carbon and nutrient uptake and water quality $(\mathrm{pH}$, temperature, etc) on microalgal growth.

\subsection{Previous mathematical model studies}

Many different studies have been undertaken to establish a mathematical model to successfully predict algal growth in batch system. These have included:

- the fitting of experimental data to a biokinetic model for a batch PBR [8];

- the representation of the impact of light intensity (attenuated by culture media depth) and temperature on the photoautotrophic growth of Cyanothece [9] (and subsequent scale-up to pilot scale for biomass production [10], [11]);

- the optimisation of nutrient removal by microlagae, calibrated and validated with both repirometric and titrimetric data [10];

- the construction and experimental validation of a model of microlagae biomass and lipids accumulation in a PBR using initial TN, light intensity and temperature as the primary inputs [11];

- a simple model to predict biomass values, using kinetic growth parameters, as a function of HRT to maximise biomass productivity in a continuous PBR [12].

Despite the large number of mathematical models presented in the literature to simulate PBRs, no models have been proposed which comprehensively incorporate all phenomena relevant to combined biomass growth and nutrient removal from wastewater. Most of the published models, including the most recent [10], do not address the effects of the initial nutrient concentration on both the treated wastewater quality and algal growth. Whilst the classic mathematical dynamic model of microalgae growth proposed by Droop [13, 14] accounts for the dilution rate and effects of inorganic nitrogen concentration, the impact of all other parameters (including $\mathrm{CO}_{2}$ gas concentration $C_{c, g}$, light irradiation intensity $I$, and the nutrient uptake rate) is neglected. Models have otherwise been developed for lipid synthesis as it relates to algal growth rate and $\mathrm{N}$ uptake [15], and luxury uptake of phosphorus as polyphosphate as a function of the available $\mathrm{P}$, light intensity and temperature so as to provide $\mathrm{P}$ removal efficiency [16]. Thus, whilst a wide range of base parameter values that have been employed in these models (Table 1), these have not led to the same sort of treated effluent nutrient concentration profile outputs as provided by classical biological nutrient removal (BNR) models [17]. 
Table 1: Parameter values assumed in recently-published PBR mathematical models, batch processes

\begin{tabular}{|c|c|c|c|c|c|c|c|c|c|c|c|c|}
\hline $\begin{array}{l}P B R \\
\text { configuration }\end{array}$ & $\begin{array}{c}\mu_{\max } \\
d^{-1}\end{array}$ & $\begin{array}{l}k_{d} \\
d^{-1}\end{array}$ & $\begin{array}{c}C_{c, g} \\
\% v / v\end{array}$ & $\begin{array}{c}Q_{g} \\
v v m\end{array}$ & $\begin{array}{c}H R T \\
d^{-1}\end{array}$ & $\begin{array}{c}K_{l, C} \\
d^{-1}\end{array}$ & $\begin{array}{l}\mathrm{TP} \\
m g \\
L^{-1}\end{array}$ & $\begin{array}{l}\mathrm{TN}, \\
m g \\
L^{-1}\end{array}$ & $\begin{array}{l}\mathrm{TC}, \\
m g \\
L^{-1}\end{array}$ & $\begin{array}{l}T, \\
C^{o}\end{array}$ & $\begin{array}{c}I, \\
\mu E m^{-2} \\
s^{-1}\end{array}$ & Ref. \\
\hline Classical PBR & $\begin{array}{l}0.1- \\
0.52\end{array}$ & -- & $0.03^{\mathrm{a}}$ & 0.5 & $3.3^{\mathrm{s}}$ & -- & 12.7 & $\begin{array}{c}54.5 \\
8\end{array}$ & $384^{c}$ & $20 \pm 3$ & 90 & [8] \\
\hline Tubular PBR & 1.75 & -- & 10 & 0.028 & $1.36^{\mathrm{b}}$ & -- & -- & -- & -- & $25-37$ & $275-23$ & [9] \\
\hline Flat plate PBR & 0.156 & -- & -- & -- & $1-10^{b}$ & -- & -- & -- & -- & 23 & 150 & [18] \\
\hline Bubbled PBR & -- & -- & $0.03^{\mathrm{a}}$ & -- & 280 & -- & 1.12 & 12 & -- & 25 & $250-30$ & [19] \\
\hline $\begin{array}{l}\text { Breeding } \\
\text { reactor }\end{array}$ & $0.1-2$ & -- & $0.03^{\mathrm{a}}$ & -- & -- & $5-10$ & 4 & 6 & -- & 26 & $130-90$ & [10] \\
\hline $\begin{array}{l}\text { Combine algal } \\
\text { unit }\end{array}$ & $0.1-11$ & -- & 2 & 2.5 & -- & $0.3-19$ & -- & -- & -- & 20 & 90 & [20] \\
\hline Solix PBR & 0.6 & 0.01 & 2.5 & & 65 & -- & 1.12 & 12 & -- & $21-24$ & 200 & [11] \\
\hline Helical PBR & 1.77 & -- & 4 & 0.047 & $\begin{array}{l}15- \\
2.5^{\mathrm{b}}\end{array}$ & -- & 5 & 260 & 5 & $24-33$ & 156 & [21] \\
\hline BIOSTAT PBR & 0.52 & -- & 10 & 16 & 2.5 & -- & -- & -- & -- & 25 & -- & {$[22]$} \\
\hline Flat panel PBR & 0.94 & -- & 5 & 0.63 & $\begin{array}{l}3.4^{-} \\
1.1^{\mathrm{b}}\end{array}$ & 1.63 & 31 & -- & -- & 20 & 250 & [12] \\
\hline
\end{tabular}

$\mu_{\max }$ maximum specific growth rate; $k_{d}$ biomass loss rates; $Q_{g}$ gas flow rate; vvm = volume gas per volume liquid per minute; HRT hydraulic residence time; $K_{l, C} \mathrm{CO}_{2}$ mass transfer rate; TP total phosphorus; TN total nitrogen; TC total carbon, I irradiation intensity

${ }^{\mathrm{a}}$ Atmospheric level; ${ }^{\mathrm{b}}$ Continuous or ${ }^{\mathrm{s}}$ semi continuous system; ${ }^{\mathrm{c}} \mathrm{COD}$.

There is an evident need for a numerical mathematical model capable of simulating algal growth rates as a function of initial TP, TN including the influence of $C_{c, g}$ and $I$. Such a model could then be employed to estimate nutrient removal and predicated dynamic behavior of a batch system.

\section{Materials and methods}

\subsection{Practical experiments}

The work was based on Chlorella vulgaris $C v$ (strain: CCAP 211/11B, CS-42), supplied by Australian National Algae Culture Collection/CSIRO Microalgae, and inoculated with a $10 \%$ suspension of microbiology-derived medium (MLA) [23]. The cells were cultivated in a shaker incubator at $200 \mathrm{rpm}$ and $20^{\circ} \mathrm{C}$, with continuous illumination of white fluorescent light at $50 \mu \mathrm{E}$ for three weeks inside an incubator refrigerator.

Experiments were conducted in $350 \mathrm{~mL}$ cylindrical glass columns $(\mathrm{ID}=4 \mathrm{~cm})$ with a 250 $\mathrm{mL}$ working volume. Sterilized $250 \mathrm{~mL}$ medium at different concentrations of TN $(0$ $\left.207 \mathrm{mg} \mathrm{L}^{-1}\right)$ and TP $(0-8 \mathrm{mg} / \mathrm{L})$, was inoculated with $1 \mathrm{vol} \%$ pre-cultured medium. The culture was fed continuously with filtered air, enriched with $\mathrm{CO}_{2}(0.04-5 \%)$, at a flow rate of $50 \mathrm{~mL} \mathrm{~min}{ }^{-1}$ as monitored by digital mass flow controllers (MC-100SCM, ColeParmer, USA); the inlet and outlet $\mathrm{CO}_{2}$ concentration was measured using a $\mathrm{CO}_{2}$ probable meter (G110, Geotech, UK). Continuous illumination between 100 and $250 \mu \mathrm{E}$ $\mathrm{m}^{-2} \mathrm{~s}^{-1}$, provided by adjusting the number of $8 \mathrm{~W}$ LED lights between 4 and 8 , was measured by a light meter (LI-250A, LI-COR, US \& Canada). A $5 \mathrm{~mL}$ sample was extracted daily for analysis, equating to a hydraulic and solids residence time of 50 days, and all runs lasted for 10-13 days. 
The total nitrogen (TN) and total phosphorus (TP) concentrations of the filtered liquid sample (with membrane filter, $0.45 \mu \mathrm{m}$ ) were analysed using a $\mathrm{HACH}$ kit (DR/890 Colorimeter, HACH, USA) and the total organic carbon (TOC) concentration using a Shimadzu TOC analyser. The optical density (OD) was determined by UV-Vis spectrophotometer (Jasco V - 670) at $680 \mathrm{~nm}$, and the reading converted to dry cell weight $\left(X \mathrm{~g} \mathrm{~L}^{-1}\right)$ by calibration. The specific growth rate $\mu$ was then calculated from the initial and final biomass concentrations and the corresponding cultivation time. For all nutrient tests the control sample contained $6 \mathrm{mg} \mathrm{L}^{-1} \mathrm{TP}$ and $28 \mathrm{mg} \mathrm{L}^{-1} \mathrm{TN}$, based on the typical medium MLA composition stipulated by the supplier.

\subsection{Modelling equations}

The model development proceeded through the steps indicated in Figure 1. The mathematical model used to simulate the experimental data in this study was based on the classical homogenous model for a bubble column PBR operated in batch mode [21]. The model was developed as a set of parameterized nonlinear first order differential equations defined by fundamental physical and/or chemical mechanisms and base experimental data. Biological, gas and liquid phases considered in the PBR and mass balance equations were derived according to the following assumptions:

- All cultivation conditions factors affecting $C v$ growth were encompassed, including gas flow rate, light intensity, temperature, feed water quality.

- The Henry constant $(\mathrm{H})$ was considered to be unaffected by the gas pressure: values were taken at $25^{\circ} \mathrm{C}$ and atmospheric pressure for both $\mathrm{CO}_{2}$ and $\mathrm{O}_{2}$.

- Microalgal cells were assumed to be able to fix dissolved inorganic carbon regardless of its form (i.e. $\mathrm{CO}_{2}, \mathrm{HCO}_{3}{ }^{-}$and $\mathrm{CO}_{3}{ }^{2-}$ ).

- The light intensity was sufficient to ensure growth without being impaired by dissipation by the biomass concentration but not so excessive so as to cause light limitation, with the threshold biomass concentration assumed to be $1 \mathrm{~g} \mathrm{~L}^{-1}$ [2].

- Light inhibition (due to excessive irradiation levels of $500-2500 \mu \mathrm{E} \mathrm{m}^{-2} \mathrm{~s}^{-1}[24,25]$ ) was ignored; a range of $100-250 \mu \mathrm{E} \mathrm{m}^{-2} \mathrm{~s}^{-1}$ light irradiation range was employed.

- Operation was assumed not to be limited by the nutrient or carbon concentration.

Some simplifying assumptions were made in developing the model to reduce the complexity of the model parameters:

- The gas flow rate was considered to remain constant with time and culture depth: the gas was assumed to be uniformly distributed in the cultivation medium.

- Oxygen inhibition was ignored, since it was removed to low levels in the experimental tests.

- A batch growth culture was considered, although the model could be readily adapted to a semi-batch or fed-batch reactor.

- Only autotrophic growth from light irradiation was considered: other possible growth mechanisms were ignored. 


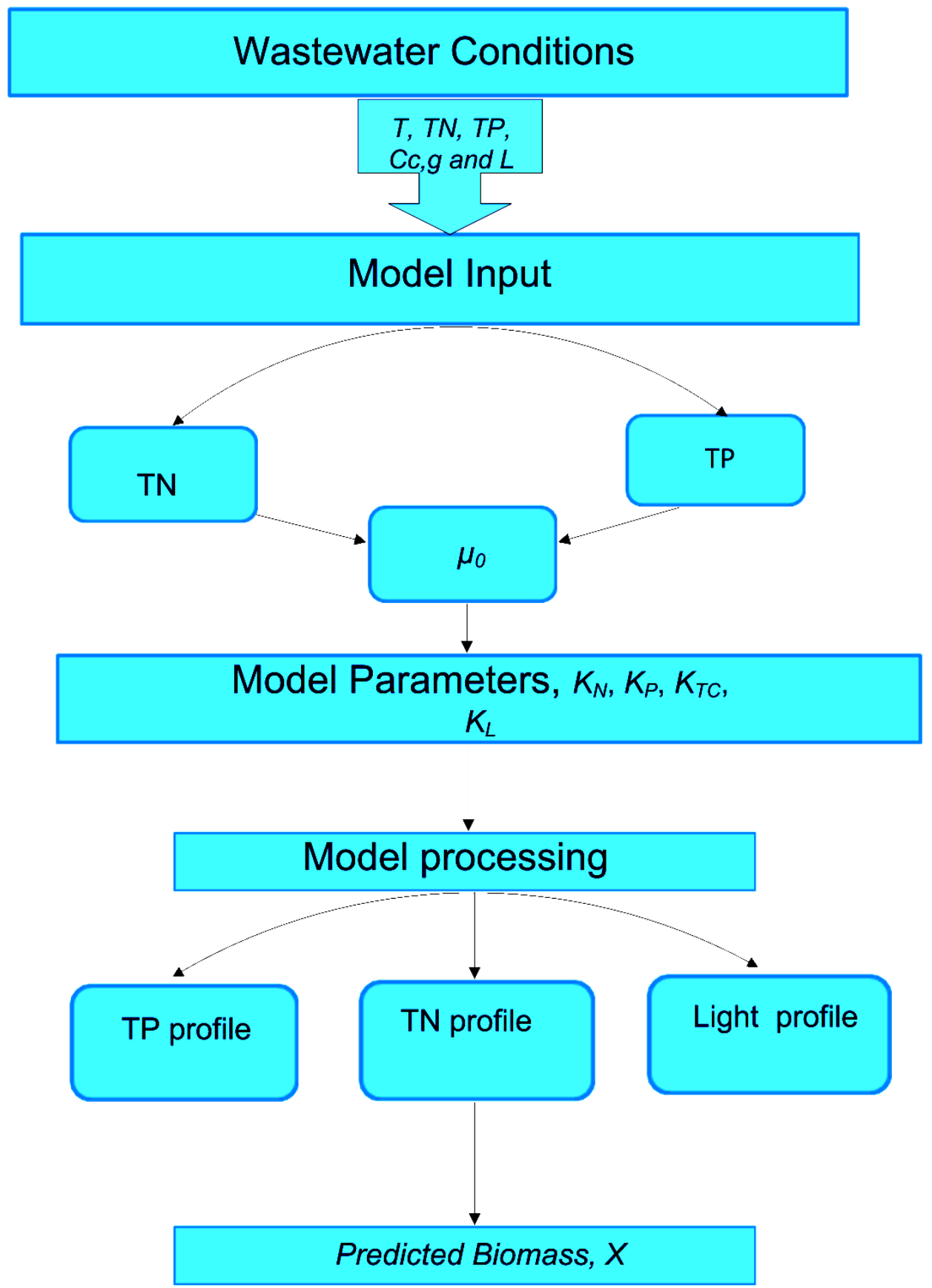

Figure 1. Modelling strategy

\subsection{Gases dynamics in liquid phase of PBRs}

The rate of $\mathrm{CO}_{2}$ transferred from the gas to liquid phase is represented by dual-film theory:

$R_{C}=k_{C}\left(C_{s}-C\right) V(1-\varepsilon)$ 
Where $k_{C}$ is the mass transfer coefficient for the transfer of $\mathrm{CO}_{2}$ from the gas phase to bulk culture phase, $C_{s}$ is the saturated concentration of $\mathrm{CO}_{2}, C$ is the concentration of inorganic carbon, $V$ the reactor volume and $\varepsilon$ the gas hold up volume. According to Henry's law:

$$
C_{s}=\frac{P y}{R T H} \mathrm{MW}_{\mathrm{HCO} 3} 1000
$$

where $P$ is the pressure, $y$ the gas phase $\mathrm{CO}_{2}$ fraction, $R$ the gas constant, $T$ the temperature, $H$ the Henry's Law constant and $\mathrm{MW}_{\mathrm{HCO} 3}$ the molar mass of bicarbonate. $k_{C}$ can be estimated from correlations available [26] for the transfer coefficient for oxygen $k_{O}$ using the aqueous phase diffusivities of $\mathrm{CO}_{2}$ and $\mathrm{O}_{2}$ ( $D_{C}$ and $D_{O}$ respectively):

$k_{C}=k_{O} \sqrt{\frac{D_{C}}{D_{O}}}$

$\varepsilon$ was estimated by volumetric expansion as proposed by Chisti [27] based on the gassed and un-gassed height of fluid ( $h_{G}$ and $h_{L}$ respectively) in each part of the PBR:

$\varepsilon=\frac{h_{G}-h_{L}}{h_{G}}$

The uptake rate of carbon by the algal culture can be expressed as a function of biomass concentration, the yield coefficient (total carbon consumed per algal biomass produced $\left.Y_{C, t o t}\right)$ and $\mu_{X}$, the algal specific growth rate:

$$
\frac{d c}{d t}=-1000 Y_{C, t o t} \mu_{X} X
$$

The total carbon dissolved in the algal culture can be obtained from substrate equations (5) and (9).

$$
\frac{d C_{\text {total }}}{d t}=k_{C}\left(C_{s}-C\right) V(1-\varepsilon)-1000 Y_{C, t o t} \mu_{X} X
$$

with appropriate initial conditions of:

$$
\left[d C_{\text {total }}\right]=\left\lfloor C_{\text {init,total }}\right\rfloor @ \mathrm{t}=0
$$

The first term on the right hand side of Equation 10 takes into account mass transfer phenomena from the gas to liquid phase and the second term the $\mathrm{CO}_{2}$ consumption and concomitant liquid phase microalgae production process. 
The mass balance for total dissolved nutrients ( $\mathrm{N}$ and $\mathrm{P}$ ) not involved in the gas liquid mass transfer phenomena can be expressed as follows:

$$
\frac{d C_{N, P}}{d t}=-1000 Y_{N, P} \mu_{X} X
$$

with appropriate initial conditions:

$$
[N, P]=\left[N_{\text {init }}, P_{\text {init }}\right] @ \mathrm{t}=0
$$

\subsection{Biomass growth rate}

The final growth rate of algal biomass, $d X / d t$, can be written as :

$$
\frac{d X}{d t}=\mu_{X} X-K_{d} X
$$

where $K_{d}$ is the biomass loss rate. According to Monod model the nutrient-limited algal growth rate $\mu_{0}$ can be expressed as

$\mu_{0}=\mu_{X}\left[\frac{S_{i}}{K_{i}+S_{i}}\right]$

where $S_{i}$ is the nutrient ( $N$ or $P$ ) concentration, $K_{i}$ the nutrient half saturation constant and $\mu_{X}$, the non-nutrient limited specific growth rate, is determined experimentally.

Specific experiments were carried out by cultivating $C v$ in batch PBRs at various initial dissolved nutrient concentrations to establish the impact on growth. Outputs were used in conjunction with Equations (16-17) to evaluate the dependency of $\mu_{0}$ on initial dissolved nutrient concentration:

$$
\begin{aligned}
& \mu_{P}=0.989\left[\frac{S_{P}}{1.65+S_{P}}\right] \\
& \mu_{N}=1.039\left[\frac{S_{N}}{8.7+S_{N}}\right]
\end{aligned}
$$

where the values of $0.989,1.039,1.65$ and 8.7 are the Monod parameters calculated from the baseline experimental data (Section 3.2). Overall, for the combined effect of $\mathrm{N}$ and $\mathrm{P}$ nutrients on the algal growth, the Double Monod model [28]:

$$
\mu_{\mathrm{N}, \mathrm{P}}=\mu_{\max }\left[\frac{S_{N}}{K_{N}+S_{N}}\right]\left[\frac{S_{P}}{K_{P}+S_{P}}\right]
$$


where $S_{N}, S_{P}$ are the respective $\mathrm{N}$ and $\mathrm{P}$ concentrations in the culture and $K_{N}, K_{P}$ the corresponding half saturation constants for nitrogen and phosphorus respectively, based on the experimental data. The specific growth rate is then given by:

$$
\mu_{0}=1.4\left[\frac{S_{N}}{6.5+S_{N}}\right]\left[\frac{S_{P}}{0.75+S_{P}}\right]
$$

where the values of $1.4,6.5$ and 0.75 are the Double Monod model parameters again calculated from the baseline experimental data (Section 3.2). Extending this equation to account for growth control substrate for both $\mathrm{N}$ and $\mathrm{P}$ :

$\mu_{\mathrm{X}}=\mu_{0}\left[\frac{S_{N}}{K_{N}+S_{N}}\right]\left[\frac{S_{P}}{K_{P}+S_{P}}\right]\left[\frac{T C_{c}}{K_{T C}+C_{c}}\right]\left[\frac{L_{a v}{ }^{n}}{K_{L}^{n}+L_{a v}{ }^{n}}\right]$

where $C_{c}$ is the total carbon dissolved in the culture media, $K_{T C}$ total carbon half saturation constant and $K_{L}$ is half saturation constant of light. The average light intensity $L_{a v}$ within the culture in cylindrical bubble PBR illuminated by a unidirectional parallel flux can be expressed by:

$$
L_{a v}=\frac{2 I}{r K X \pi}\left[1-\int_{0}^{\pi / 2} \cos (\theta) \exp (-2 r K X \cos (\theta)) d \theta\right]
$$

where $r$ represents the PBR radius. $K$ is the overall light extinction coefficient, given by:

$K=K_{c} C_{c h l}+K_{w}$

where $K_{c}$ is the chlorophyll-based light extinction coefficient of algae, $C_{c h l}$ is the chlorophyll concentration, which is a function of biomass concentration and is determined experimentally, and $K_{w}$ is the light extinction coefficient of pure water.

The combined set of ordinary differential equations (ODEs) were coded in MATLAB to correlate the time-dependent algal biomass concentration $X\left(\mathrm{~g} \mathrm{~L}^{-1}\right)$ and algal nutrient uptake functions with light intensity, and the simulations validated with the experimentally-determined $C v$ growth data. A sensitivity analysis of a parameter $P_{j}$ was conducted with respect to $X$ to assess the response of biomass concentration to changes in each model parameter to assess the validity of the simplifying assumptions (Section 2.2):

$$
\sigma_{x}=\frac{\Delta X}{\Delta P_{j}} \frac{P_{\text {jnom }}}{X_{n o m}}
$$

where $P_{\text {jnom }}$ is the parameter nominal value and $X_{\text {nom }}$ the model response when nominal parameters are used. $\mathrm{A} \pm 20 \%$ variation in $\Delta P_{j}$ was applied to obtain the test values to 
determine $\Delta X$. Four biomass profiles were used in calculating the mean profile with the standard deviation estimated from the four runs. The sensitivity coefficient for each parameter was calculated from the average spread according to the method of Bernard et al. (2001) [29].

An F-test was performed to determine the variance between the predicted and measured values using Jmp statistical discovery software (SAS version 11.2.1).

\section{Results and discussion}

\subsection{Mass transfer coefficient:}

$k_{C}$ was estimated from $k_{O}$ data using Equation 7. A previous reported correlation for bubble columns [30, 31] was used to calculate $k_{C}$ in terms of $\varepsilon$ measured at the corresponding gas flowrate. This procedure produced a $k_{C}$ of $5.8 \times 10^{-6} \mathrm{~s}^{-1}$ at a gas flowrate $50 \mathrm{~mL} \mathrm{~min}{ }^{-1}$, towards the low end of the range of values reported in the literature of $3.8 \times 10^{-6} \mathrm{~s}^{-1}$ [20] for different PBR configurations.

\subsection{Model calibration}

The influence of the parameters $T N_{\text {init }}, T P_{\text {init }}, I$ and $C_{c, g}$ on the kinetics of $C v$ was determined through mathematical simulation, and the reliability of the model data assessed using validatory experimental test data. Further experiments were carried out to evaluate the influence of the initial concentrations of dissolved inorganic carbon, $\mathrm{N}$ and $\mathrm{P}$ on algal growth by varying the concentrations of sodium bicarbonate, sodium nitrate and potassium bisphosphate in the MLA cultivation medium. The feed gas $\underline{C}_{c, g}$ was also varied at a constant $Q_{g}$ of $50 \mathrm{~mL} \mathrm{~min}^{-1}$. A pH 6-8 was maintained throughout.

Calibration was through determination of $\mu_{\max }$ from Equations 20-22 tuned through a nonlinear fitting procedure. The computed biomass concentration values were compared by the least squares method with microalgal growth experimental data. The relative error obtained by the fitting procedure was around $1 \%$. Other parameters were estimated, such as the half saturation constants for light $\left(K_{L}\right)$, carbon $\left(K_{T C}\right)$, and nutrients $\left(K_{N}\right.$ and $\left.K_{P}\right)$, the algae loss rate $\left(K_{d}\right)$, the chlorophyll-based light extinction coefficient $\left(K_{C}\right)$, the light extinction coefficient of pure water $\left(K_{w}\right)$ and the shape parameter $(n)$ were then adjusted by trial and error to obtained the best fit for the biomass concentration profile. The best fit parameters established by calibration were used in the validation step based on the growth profile data from the remaining experimental tests runs. Biomass yield values $Y_{i}$

$\left(\mathrm{g}_{\mathrm{w}} \mathrm{g}_{\text {biomass }}{ }^{-1}\right)$ were estimated according to published methods [32] from the $C v$ elemental composition, assumed to have the formula $\mathrm{C}_{1000} \mathrm{H}_{1650} \mathrm{O}_{242} \mathrm{~N}_{130} \mathrm{P}_{10} \mathrm{~S}_{4.5} \mathrm{~K}_{2.7} \mathrm{Na}_{2.5} \mathrm{Mg}_{2} \mathrm{Ca}_{1} \mathrm{Cl}_{0.2}$ [33].

Values for the shape factor parameter $n$, accounting for light limitation caused by the biomass density, were adjusted according to the assumptions presented in Section 6.1. The best-fit value obtained for $n$ was 1.4 , this value being slightly outside the range of 1.49-2.2 reported in previous studied [21, 28, 34]. Best-fit values generated by simulation during the calibration process for other parameters are shown in Table 2. 
Table 2: Summary of base parameters values

\begin{tabular}{llll}
\hline Symbol & Unit & Parameter value & Notes \\
\hline$\mu_{\max }$ & $\mathrm{s}^{-1}$ & $1.62 \times 10^{-5}$ & Current study, estimated \\
$K_{d}$ & $\mathrm{~s}^{-1}$ & $2.3 \times 10^{-6}$ & Current study, estimated \\
$K_{L}$ & $\mu \mathrm{E} \mathrm{m}^{-2} \mathrm{~s}^{-1}$ & 16 & Current study, estimated \\
$K$ & $\mathrm{~m}^{2} \mathrm{~g}^{-1}$ & $2.5 \times 10^{-1}$ & Current study, estimated \\
$K_{p}$ & $\mathrm{~g} \mathrm{~L}^{-1}$ & $4 \times 10^{-2}$ & Current study, estimated \\
$K_{N}$ & $\mathrm{~g} \mathrm{~L}^{-1}$ & $3.7 \times 10^{-1}$ & Current study, estimated \\
$K_{T C}$ & $\mathrm{~g} \mathrm{~L}^{-1}$ & $5 \times 10^{-1}$ & Current study, estimated \\
$\mathrm{N}$ & - & 1.42 & Current study, estimated \\
$H_{e, C}$ & - & $8.32 \times 10^{-1}$ & {$[35]$} \\
$H_{e, O}$ & - & $3.2 \times 10^{-2}$ & {$[35]$} \\
$\mathrm{Y}_{\text {ctot }}$ & $\mathrm{g}_{\mathrm{c}} \mathrm{g}_{\text {biomass }}{ }^{-1}$ & $5 \times 10^{-1}$ & Current Study, estimated \\
$Y_{p}$ & $\mathrm{~g}_{\mathrm{P}} \mathrm{g}_{\text {biomass }}$ & $2.4 \times 10^{-2}$ & Current Study, estimated \\
$Y_{N}$ & $\mathrm{~g}_{\mathrm{N}} \mathrm{g}_{\text {biomass }}{ }^{-1}$ & $2 \times 10^{-1}$ & Current Study, estimated \\
$Y_{O}$ & $\mathrm{~g}_{\mathrm{O} 2} \mathrm{~g}_{\text {biomass }}{ }^{-1}$ & 0.534 & $(--),[36,37]$ \\
$\mathrm{d}_{\mathrm{B}}$ & $\mathrm{m}$ & $1 \times 10^{-6}$ & Current Study, estimated \\
$D_{C}$ & $\mathrm{~m}^{2} \mathrm{~s}^{-1}$ & $14.7 \times 10^{-9}$ & {$[30]$} \\
$D_{O}$ & $\mathrm{~m}^{2} \mathrm{~s}^{-1}$ & $8.0 \times 10^{-9}$ & {$[30]$} \\
$K_{\text {La,C }}$ & $\mathrm{s}^{-1}$ & $5.78 \times 10^{-6}$ & Current Study, estimated \\
$K_{w}$ & $\mathrm{~cm}^{-1}$ & 0.0018 & {$[38]$} \\
\hline
\end{tabular}

\subsection{Model validation}

The model was validated by comparing the experimentally-determined biomass concentration profiles for the remaining five sets of experimental conditions with model predications using the parameter values determined by the calibration process. According to growth profile data for a range of different initial nutrient concentrations $\left(T N_{\text {init }}=28\right.$ $\left.207 \mathrm{mg} \mathrm{L}^{-1} ; T P_{\text {init }}=6-8 \mathrm{mg} \mathrm{L}^{-1}\right)$ and gaseous carbon concentrations $\left(C_{c, g}=0.03-5 \%\right)$, the is reasonable fit between the experimental and model data (Fig. 2). The base parameters identified (Table 2) were thus used for subsequent sensitivity analysis (Section 3.4) and nutrient removal profile modelling (Section 3.5).

\subsection{Sensitivity and regression analysis}

The sensitivity of the growth profile to the parameters $L_{k}, K_{N}, T C_{K}, K_{p}, K_{d}$ and $\mu_{\max }$ was examined based on the experimental conditions of $C_{c, g}=2.5 \%, T N_{\text {init }}=28 \mathrm{mg} \mathrm{L}^{-1}, T P_{\text {init }}$ $=6 \mathrm{mg} \mathrm{L}^{-1}$ and $I=250 \mu \mathrm{E} \mathrm{m}^{-2} \mathrm{~s}^{-1}$ used for the calibration step. The pre-defined model constants (Table 1) were used as base values and individually varied by $\pm 20 \%$ and the impact on $X$. The mean predicted profile from four runs for each parameter is shown in Fig. 3 with the corresponding sensitivity coefficient estimated from Equation 23, with sensitivity increasing with increasing $\sigma_{x}$. According to Figure $3, \mu_{\max }\left(\sigma_{x}=0.52\right)$ and the biomass loss rate $\left(K_{d}, \sigma_{\mathrm{x}}=0.11\right)$ were the most sensitive parameters followed by considerably reduced sensitivity for the half saturation constant for carbon and light at $\left(\sigma_{x}\right.$ $=0.008$ and 0.004 for $K_{T C}$ and $K_{L}$ respectively). Sensitivity to $\mu_{\max }$ has been previously reported [39] and reflects the importance of this parameter on the accuracy of model prediction. The influence of remaining four parameters on biomass profile was negligible. 


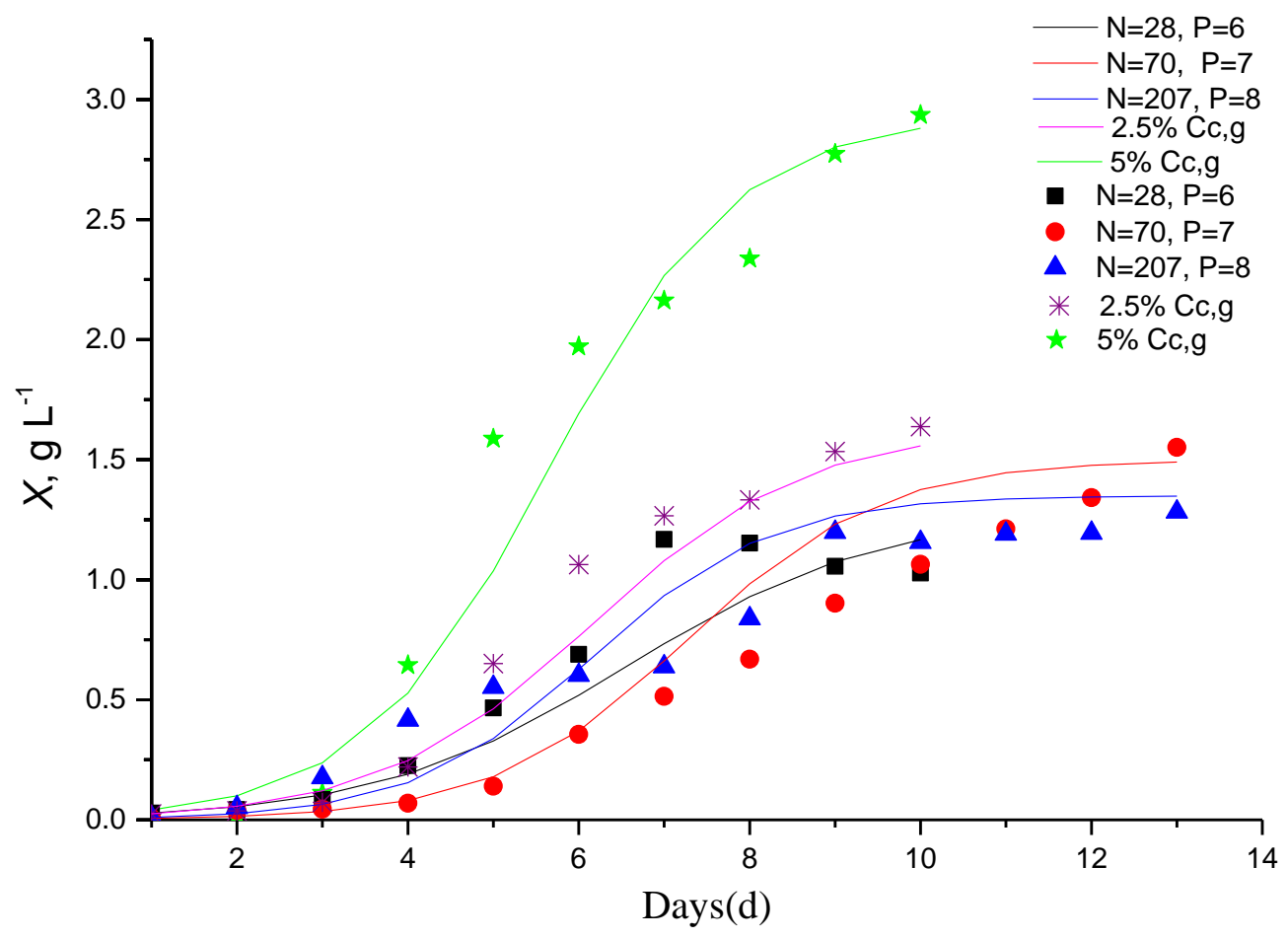

Figure 2. Model verification applying different cultivation conditions $\left(T N_{i}, T P_{i}, C_{c, g}\right.$ and $I$ for experimental (data points) and model (continuous trend) data

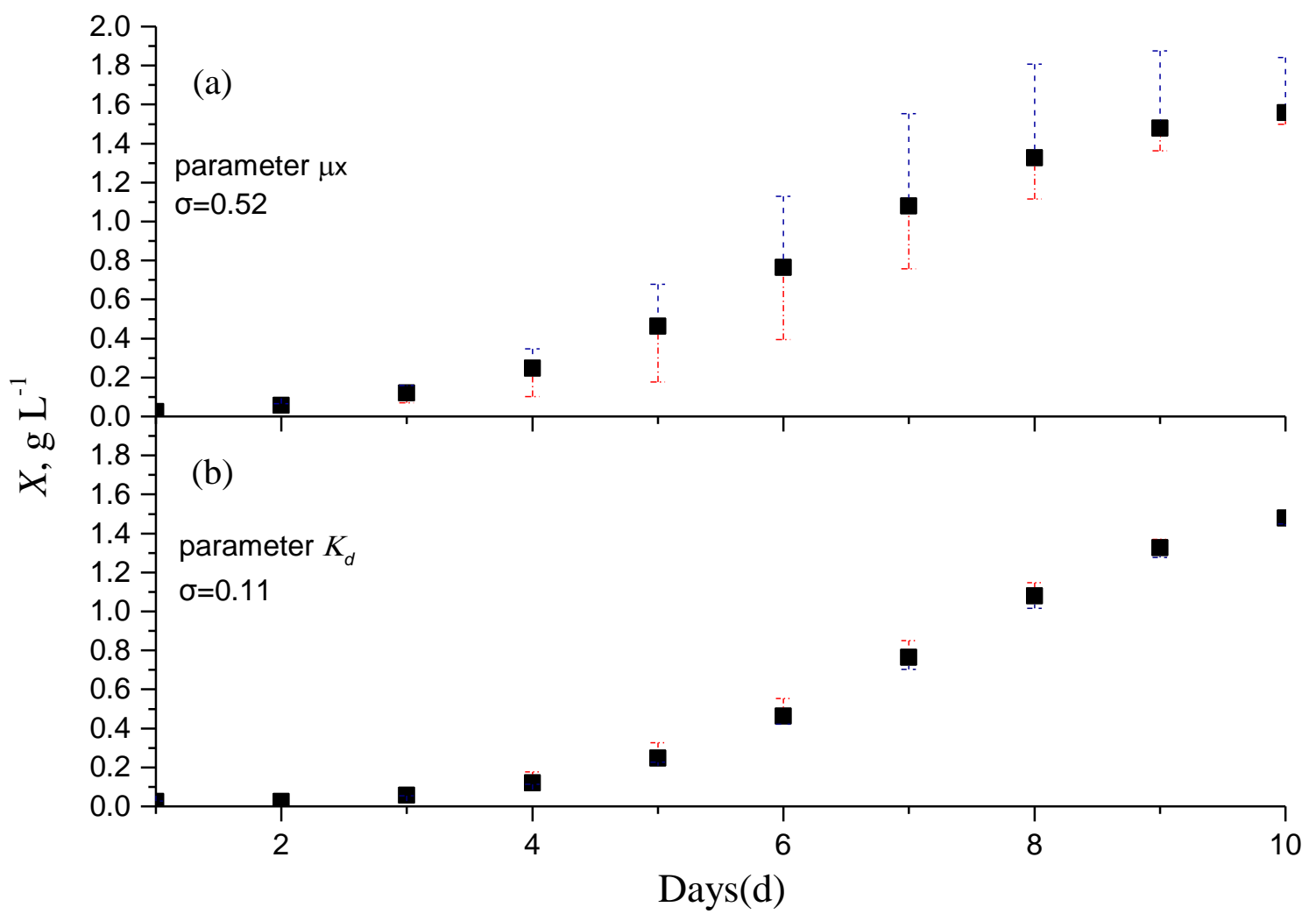

Figure 3. Predicted mean algal biomass concentration profile and its variation based on $\pm 20 \%$ variation in (a) $\mu_{X}$, and (b) $K_{d}$, based on from four runs. 
The model was further validated by applying the regression analysis for the experimental and predicted growth profiles using SAS software. Significance of the fits achieved between the measured and predicated data (Fig. 4) is illustrated by $\mathrm{R}^{2}$ values of 0.94 and $\mathrm{p}$ values below 0.0001 for the all validated points. The model appears to reflect the growth dynamics at various values of $T N_{\text {init }}, T P_{i n i t}, I$ and $C_{c, g}$ with reasonable accuracy, comparable to that reported by Wang et al [40] who investigated the kinetics of nutrient removal and characterised the extracellular polymeric substances (EPS) generated. The specific growth rate $\mu_{\max }$ calculated from Eq. 18 was found to be the most sensitive parameter .

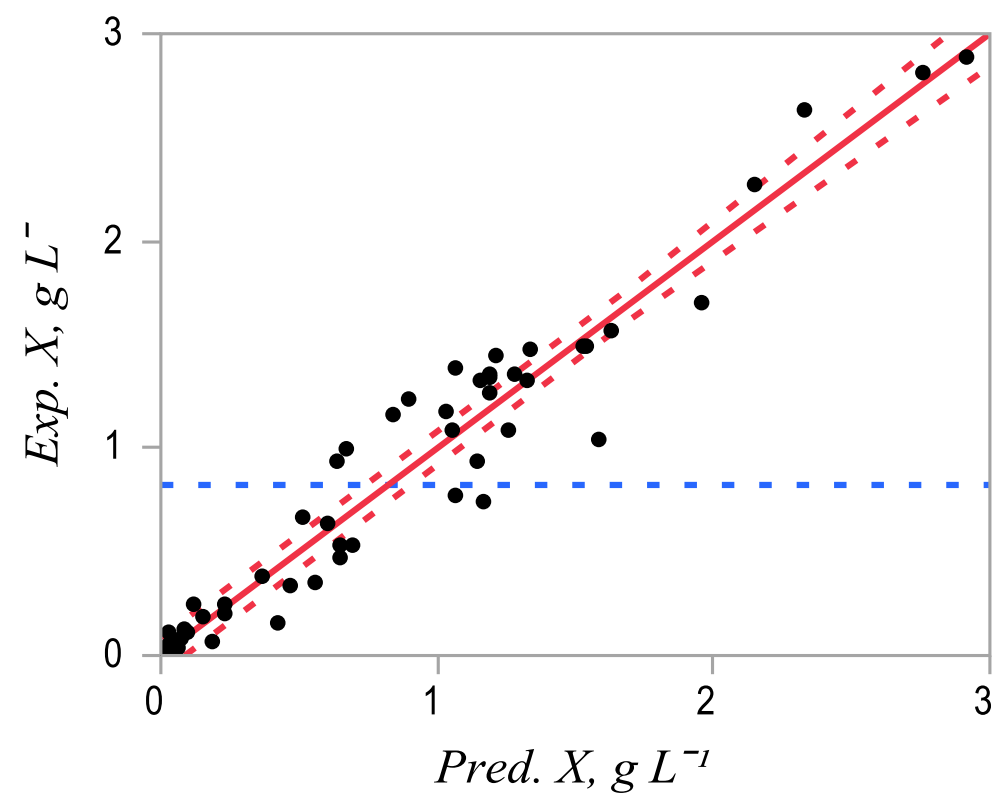

Figure 4. Regression analysis of fit between predicted and experimental biomass concentration $\mathrm{R}^{2}=$ $0.94, \mathrm{P}=0.0001$ and $\mathrm{p}>\mathrm{F}=<0.0001$ (i.e. significant). Dotted curved lines indicate $>95 \%$ confidence bands; horizontal dotted lines represent mean of the $\mathrm{Y}$ leverage residuals (i.e. the measure of agreement with the model).

\subsection{Nutrient removal}

The evolution of nutrient uptake and algal growth kinetics as a function of $T N_{\text {init }}$ and $T P_{\text {init }}$ was modelled and the outputs compared with experimental data. Modelled outputs were based on Equation 12 and encompassed the yield coefficient for total $\mathrm{N}$ or $\mathrm{P}\left(Y_{N, P}\right)$, $\mu_{x}$ and biomass concentration $X$, each of these parameters directly affecting the nutrient uptake rate.

Nutrient consumption transients (Fig. 5a-d) indicated rapid removal of $\mathrm{P}$ to $100 \%$ removal, such that it becomes limited by around 6 days at the lowest $T P_{\text {init }}$ of $6 \mathrm{mg} \mathrm{L}^{-1}$ (Fig. 5a). Whilst the extracellular phosphorous is depleted rapidly in the cultivation medium, the cells continued to grow over the period of the experiment (Fig. 5a). The luxury uptake of nutrients and storage for later growth is a well-established phenomenon in phytoplankton [14], although this does not influence the $\mathrm{P}$ uptake rate. TN removal efficiencies of $80-99 \%$ were recorded after 10-13 days for $T N_{\text {init }}$ concentrations up to 70 
mg L $\mathrm{L}^{-1}$, whilst only $60 \%$ of the $\mathrm{TN}$ was removed after 13 days at the highest $T N_{\text {init }}$ employed of $207 \mathrm{mg} \mathrm{L}^{-1}$ (Fig. 5c). The model appears to adequately predict the dynamic depletion of TN and TP in the cultivation medium, along with algal biomass production (Fig. 4), over the ranges of initial nutrient concentration (Figs. 5a,c) and feed gas $\mathrm{CO}_{2}$ concentration (Figs. 5b,d) studied.

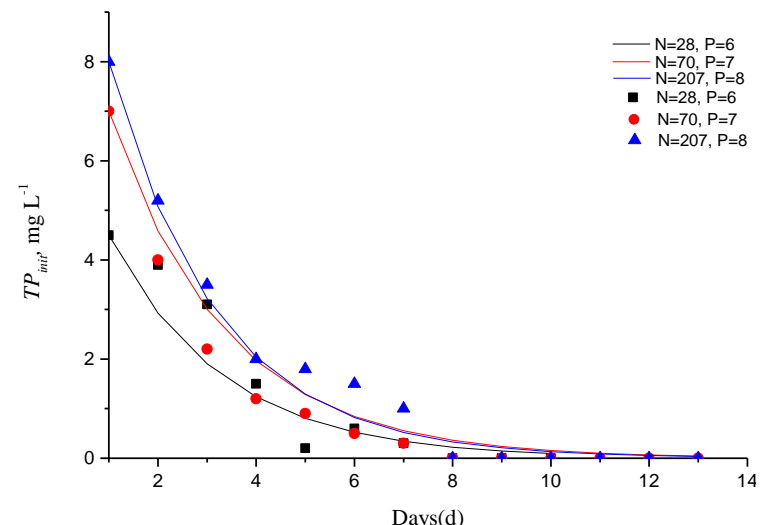

(a)

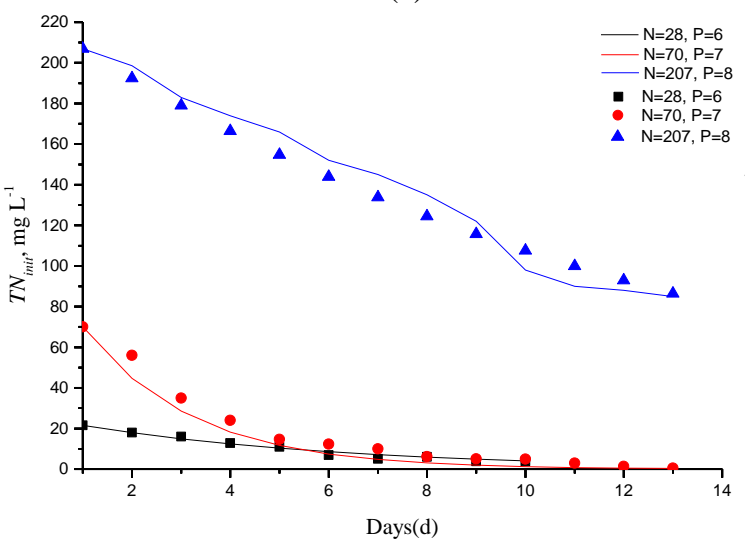

(c)

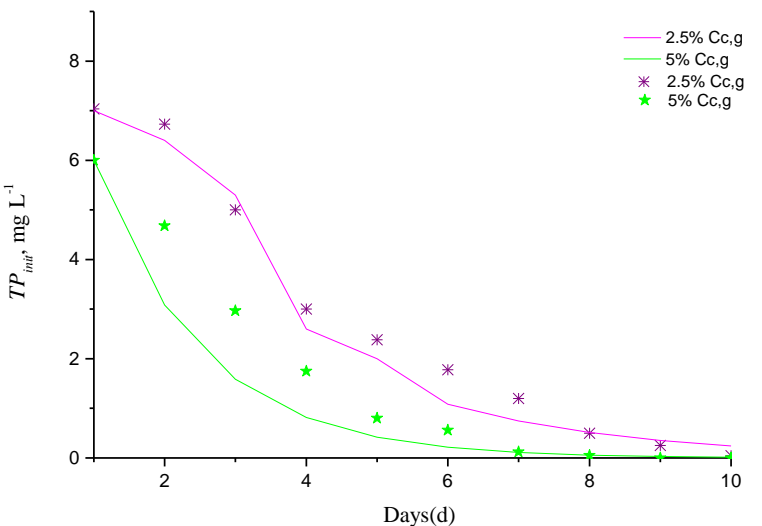

(b)

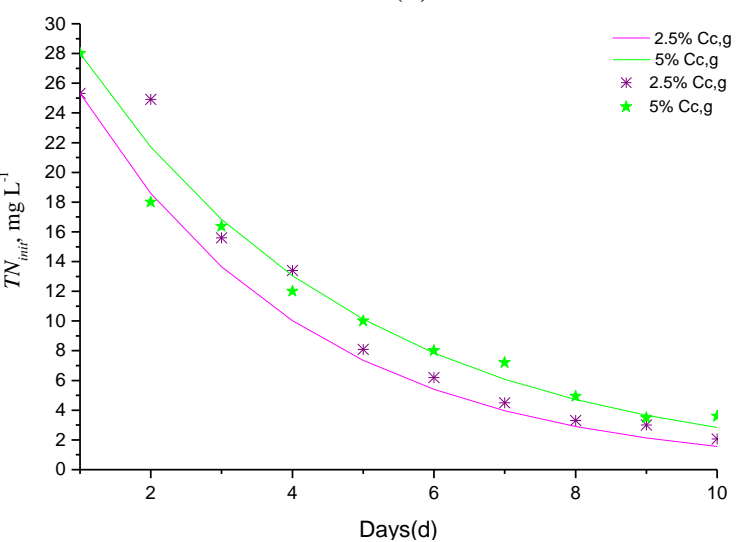

(d)

Figure 5. Evolution of total nutrient concentration under different conditions of initial aqueous nutrient concentration (a, c: $C_{c, g}=0.03 \%$,) and feed gas $\mathrm{CO}_{2}$ concentration (b, d: $T P_{\text {init }}$ and $T N_{\text {init }}=6$ and $28 \mathrm{mg} \mathrm{L}^{-1}$ respectively)

\subsection{Light attenuation profile}

The predicted average irradiance $I_{a v}$ profiles over the course of the test period are shown in Figure 6. In all cases examined it was confirmed that the limiting step for autotrophic PBR operation was the availability of light energy: the maximum productivity is dictated by rate at which the light can be absorbed and transformed into biomass.

There was a reduction in biomass concentration (of 1.6 and $2.9 \mathrm{~g} \mathrm{~L}^{-1}$ ) when the microalgae cells were illuminated at 200 and $250 \mu E \mathrm{~m}^{-2} \mathrm{~s}^{-1}$ and fed with 5 and $2.5 \% \mathrm{CO}_{2}$ gas respectively. Evidence therefore suggests that for irradiance values above the light saturation point photo-oxidation takes place, damaging the photosystem and inhibiting photosynthesis and microalgae growth [41]. Under such circumstances, the photoinhibition rate (which takes place at all irradiance vales) exceeds the rate of repair of the 
algal cells [42]. However, below the light saturation point the expected proportional increase in biomass productivity and in $\mathrm{CO}_{2}$ uptake, from photosynthesis, with increasing light irradiance was observed. The photosynthetic rate is greater at lower biomass concentrations due to the increased light availability associated with the higher light transmission through the suspension.
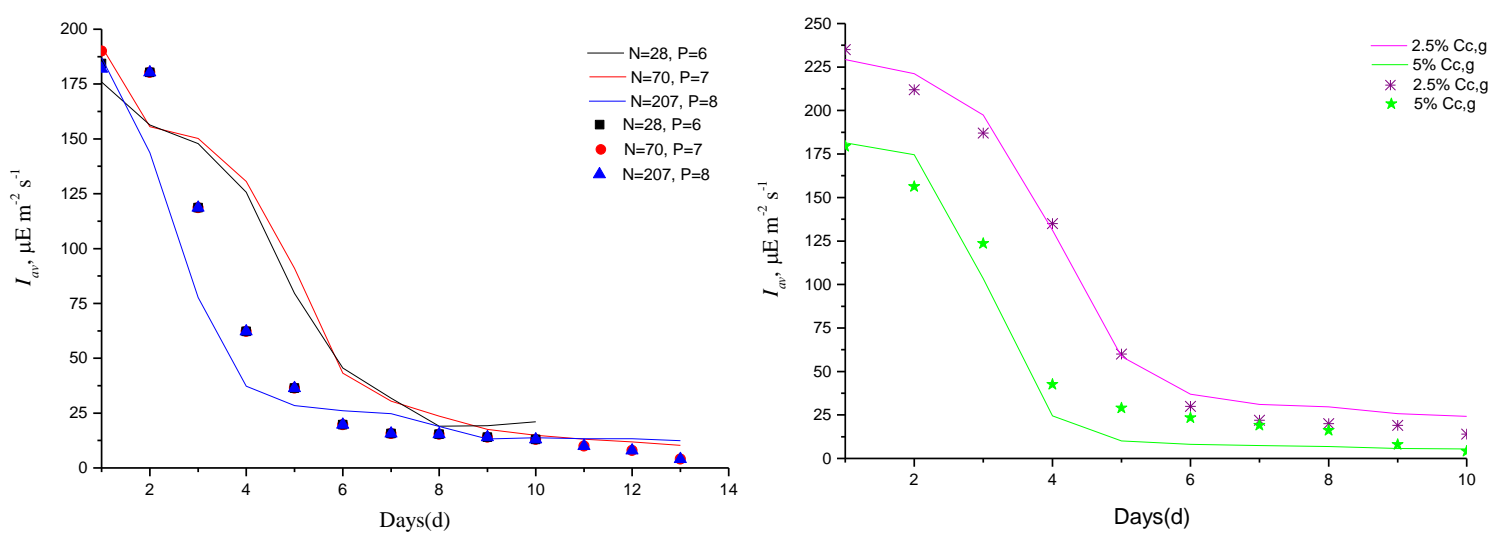

Figure 6. Average irradiance $I_{a v}$ profile during experiment period of 10 days in dished line and the predicated response in solid line.

The proposed model (combining growth and light profile) was fitted to experimental data conducted under different light intensities utilizing only a single set of parameters. The light model parameters, the half saturation constant and overall extinction coefficient were estimated experimentally as before (Table 1), with the parameter estimation based on non-linear least square fitting of the light model-predicted data to that derived from experiments conducted at different light intensities. These parameters were then numerically optimized to obtain a best fit of the model to experiment data using the simplex search algorithm of MATLAB [43]. The term $n$ (Eq.20) takes account the abruptness of the curve in the transition from low to high irradiance. The half saturation constant for photosynthesis, $L_{k}$, was determined experimentally by measuring the kinetic growth constant under different light intensities. Since the average irradiance at the end of the cultivation period was greater than the half saturation constant for light $I_{k}$ of $16 \mu E$ $\mathrm{m}^{-2} \mathrm{~s}^{-1}$, the cultures were not predominantly photo-limited and the non-linear behavior response to the light attenuation caused by absorption and scattering associated with the biomass increase during the growth phase.

\section{Conclusions}

The dynamic behavior of an algal photobioreactor (PBR) has been modelled with reference to both biomass growth and nutrient uptake and associated removal from a water stream. The model was calibrated was through using a base set of experimental conditions of feed gas $\mathrm{CO}_{2}$ concentration $\left(C_{c, g}=2.5 \%\right)$, initial nutrient concentration $\left(T N_{\text {init }}\right.$ and $T P_{\text {init }}=28$ and $6 \mathrm{mg} \mathrm{L}^{-1}$ respectively), and an irradiation intensity $(I)$ of 250 $\mu \mathrm{E} \mathrm{m}^{-2} \mathrm{~s}^{-1}$. 
The model outputs were found to be sensitive only to the maximum specific growth rate $\left(\mu_{\max }\right)$ and the biomass loss rate $K_{d}$, with a possible maximum $\pm 46 \%$ deviation in the computed algal biomass concentration $(X)$ associated with a $\pm 20 \%$ variation in $\mu_{\max }$. The calibrated model was otherwise able to predict the biomass concentration $X$ with reasonable accuracy: regression analysis revealed a correlation coefficient $\left(R^{2}\right)$ of 0.94 for mathematically-predicted vs. experimentally-determined values of $X$ over a wide range of input parameter values of feed gas and initial nutrient concentrations. Dynamic nutrient removal was similarly accurately predicted as reflected in the corresponding $\mathrm{R}^{2}$ values of 1.00 and 0.95 for the $\mathrm{N}$ and $\mathrm{P}$ profiles respectively. Predicted values based on the determined average light profile were slightly less accurate, with $\mathrm{R}^{2}$ values of 0.91 .

The calibrated model has been successfully demonstrated for the prediction of algal growth and nutrient removal, encompassing the prediction of the light profile within the biomass bulk as a function of biomass concentration. The latter would be expected to inform the appropriate dilution ratio in a continuous process. However, further work is required to determined how far the modelling approach can be extended to other operating conditions, reactor configurations and algal species.

\section{References}

[1] J. C. Weissman, R. P. Goebel, and J. R. Benemann, "Photobioreactor design: mixing, carbon utilization, and oxygen accumulation," Biotechnology and bioengineering, vol. 31, pp. 336-344, 1988.

[2] A. Richmond, Handbook of Microalgal Culture, 2007.

[3] Y. Chisti, "Biodiesel from microalgae beats bioethanol," Trends in biotechnology, vol. 26, pp. 126-131, 2008.

[4] J. A. Berges, D. O. Charlebois, D. C. Mauzerall, and P. G. Falkowski, "Differential effects of nitrogen limitation on photosynthetic efficiency of photosystems I and II in microalgae," Plant Physiology, vol. 110, pp. 689-696, 1996.

[5] S. A. Scott, M. P. Davey, J. S. Dennis, I. Horst, C. J. Howe, D. J. Lea-Smith, et al., "Biodiesel from algae: challenges and prospects," Current opinion in biotechnology, vol. 21, pp. 277-286, 2010.

[6] A. Parmar, N. K. Singh, A. Pandey, E. Gnansounou, and D. Madamwar, "Cyanobacteria and microalgae: a positive prospect for biofuels," Bioresource technology, vol. 102, pp. 10163-10172, 2011.

[7] Y. Kitaya, L. Xiao, A. Masuda, T. Ozawa, M. Tsuda, and K. Omasa, "Effects of temperature, photosynthetic photon flux density, photoperiod and $\mathrm{O} 2$ and $\mathrm{CO} 2$ concentrations on growth rates of the symbiotic dinoflagellate, Amphidinium sp," in Nineteenth International Seaweed Symposium, 2009, pp. 287-292.

[8] F. Z. Mennaa, Z. Arbib, and J. A. Perales, "Urban wastewater treatment by seven species of microalgae and an algal bloom: Biomass production, $\mathrm{N}$ and $\mathrm{P}$ removal kinetics and harvestability," Water research, vol. 83, pp. 42-51, 2015.

[9] P. Dechatiwongse, S. Srisamai, G. Maitland, and K. Hellgardt, "Effects of light and temperature on the photoautotrophic growth and photoinhibition of nitrogen-fixing cyanobacterium Cyanothece sp. ATCC 51142," Algal Research, vol. 5, pp. 103-111, 2014. 
[10] B. Decostere, J. De Craene, S. Van Hoey, H. Vervaeren, I. Nopens, and S. W. Van Hulle, "Validation of a microalgal growth model accounting with inorganic carbon and nutrient kinetics for wastewater treatment," Chemical Engineering Journal, vol. 285, pp. 189-197, 2016.

[11] J. Quinn, L. De Winter, and T. Bradley, "Microalgae bulk growth model with application to industrial scale systems," Bioresource technology, vol. 102, pp. 5083-5092, 2011.

[12] J. Ruiz, P. Álvarez-Díaz, Z. Arbib, C. Garrido-Pérez, J. Barragán, and J. Perales, "Performance of a flat panel reactor in the continuous culture of microalgae in urban wastewater: prediction from a batch experiment," Bioresource technology, vol. 127, pp. 456-463, 2013.

[13] M. Droop, "Vitamin B12 and marine ecology. IV. The kinetics of uptake, growth and inhibition in Monochrysis lutheri," J. Mar. Biol. Assoc. UK, vol. 48, pp. 689-733, 1968.

[14] M. Droop, "25 Years of Algal Growth Kinetics A Personal View," Botanica marina, vol. 26, pp. 99-112, 1983.

[15] A. Packer, Y. Li, T. Andersen, Q. Hu, Y. Kuang, and M. Sommerfeld, "Growth and neutral lipid synthesis in green microalgae: a mathematical model," Bioresource technology, vol. 102, pp. 111-117, 2011.

[16] N. Powell, A. N. Shilton, S. Pratt, and Y. Chisti, "Factors influencing luxury uptake of phosphorus by microalgae in waste stabilization ponds," Environmental science \& technology, vol. 42, pp. 5958-5962, 2008.

[17] M. Van Loosdrecht, C. Hooijmans, D. Brdjanovic, and J. Heijnen, "Biological phosphate removal processes," Applied Microbiology and Biotechnology, vol. 48, pp. 289-296, 1997.

[18] E. Sforza, M. Enzo, and A. Bertucco, "Design of microalgal biomass production in a continuous photobioreactor: an integrated experimental and modeling approach," Chemical Engineering Research and Design, vol. 92, pp. 1153-1162, 2014.

[19] F. García-Camacho, A. Sánchez-Mirón, E. Molina-Grima, F. Camacho-Rubio, and J. Merchuck, "A mechanistic model of photosynthesis in microalgae including photoacclimation dynamics," Journal of theoretical biology, vol. 304, pp. 1-15, 2012.

[20] B. Decostere, N. Janssens, A. Alvarado, T. Maere, P. Goethals, S. W. Van Hulle, et al., "A combined respirometer-titrimeter for the determination of microalgae kinetics: Experimental data collection and modelling," Chemical engineering journal, vol. 222, pp. 85-93, 2013.

[21] A. Concas, M. Pisu, and G. Cao, "Novel simulation model of the solar collector of BIOCOIL photobioreactors for CO 2 sequestration with microalgae," Chemical Engineering Journal, vol. 157, pp. 297-303, 2010.

[22] S. J. Yoo, J. H. Kim, and J. M. Lee, "Dynamic modelling of mixotrophic microalgal photobioreactor systems with time-varying yield coefficient for the lipid consumption," Bioresource technology, vol. 162, pp. 228-235, 2014.

[23] C. J. Bolch and S. I. Blackburn, "Isolation and purification of Australian isolates of the toxic cyanobacteriumMicrocystis aeruginosa Kütz," Journal of Applied Phycology, vol. 8, pp. 5-13, 1996.

[24] S. Jensen and G. Knutsen, "Influence of light and temperature on photoinhibition of photosynthesis inSpirulina platensis," Journal of applied phycology, vol. 5, pp. 495-504, 1993.

[25] A. Vonshak and R. Guy, "Photoadaptation, photoinhibition and productivity in the bluegreen alga, Spirulina platensis grown outdoors," Plant, Cell \& Environment, vol. 15, pp. 613-616, 1992. 
[26] Y. Shah, B. G. Kelkar, S. Godbole, and W. D. Deckwer, "Design parameters estimations for bubble column reactors," AIChE Journal, vol. 28, pp. 353-379, 1982.

[27] Y. Chisti, "Biodiesel from microalgae," Biotechnology advances, vol. 25, pp. 294-306, 2007.

[28] E. M. Grima, F. G. Camacho, J. S. Pérez, F. A. Fernandez, and J. F. Sevilla, "Evaluation of photosynthetic efficiency in microalgal cultures using averaged irradiance," Enzyme and microbial technology, vol. 21, pp. 375-381, 1997.

[29] O. Bernard, Z. Hadj-Sadok, D. Dochain, A. Genovesi, and J. P. Steyer, "Dynamical model development and parameter identification for an anaerobic wastewater treatment process," Biotechnology and bioengineering, vol. 75, pp. 424-438, 2001.

[30] K. Yamaberi, M. Takagi, and T. Yoshida, "Nitrogen depletion for intracellular triglyceride accumulation to enhance liquefaction yield of marine microalgal cells into a fuel oil," Journal of Marine Biotechnology, vol. 6, pp. 44-48, 1998.

[31] E. Sada, H. Kumazawa, C. H. Lee, and H. Narukawa, "Gas-liquid interfacial area and liquid-side mass-transfer coefficient in a slurry bubble column," Industrial \& engineering chemistry research, vol. 26, pp. 112-116, 1987.

[32] G. Stephanopoulos, A. A. Aristidou, and J. Nielsen, Metabolic engineering: principles and methodologies: Academic press, 1998.

[33] J. A. Raven and R. J. Geider, "Temperature and algal growth," New phytologist, pp. 441461, 1988.

[34] T. Bannister, "Comparison of Kiefer-Mitchell and Bannister-Laws algal models," Limnology and oceanography, vol. 35, pp. 972-979, 1990.

[35] R. H. P. a. D. Green., "Perry's chemical engineer's handbook," New York : McGraw Hill 2008.

[36] J. Li, N. S. Xu, and W. W. Su, "Online estimation of stirred-tank microalgal photobioreactor cultures based on dissolved oxygen measurement," Biochemical Engineering Journal, vol. 14, pp. 51-65, 2003.

[37] C. Paille, J. Albiol, R. Curwy, C. Lasseur, and F. Godia, "FEMME: a precursor experiment for the evaluation of bioregenerative life support systems," Planetary and Space Science, vol. 48, pp. 515-521, 2000.

[38] A. Sciandra, "Study and modelling of a simple planktonic system reconstituted in an experimental microcosm," Ecological modelling, vol. 34, pp. 61-82, 1986.

[39] S. R. Ronda, C. Kethineni, L. C. P. Parupudi, V. B. S. C. Thunuguntla, S. Vemula, V. S. Settaluri, et al., "A growth inhibitory model with SOx influenced effective growth rate for estimation of algal biomass concentration under flue gas atmosphere," Bioresource technology, vol. 152, pp. 283-291, 2014.

[40] M. Wang, W. C. Kuo-Dahab, S. Dolan, and C. Park, "Kinetics of nutrient removal and expression of extracellular polymeric substances of the microalgae, Chlorella sp. and Micractinium sp., in wastewater treatment," Bioresource technology, vol. 154, pp. 131137, 2014.

[41] I. S. Suh and C.-G. Lee, "Photobioreactor engineering: design and performance," Biotechnology and Bioprocess Engineering, vol. 8, pp. 313-321, 2003.

[42] E. Molina, J. Fernández, F. Acién, and Y. Chisti, "Tubular photobioreactor design for algal cultures," Journal of biotechnology, vol. 92, pp. 113-131, 2001.

[43] V. O. Adesanya, M. P. Davey, S. A. Scott, and A. G. Smith, "Kinetic modelling of growth and storage molecule production in microalgae under mixotrophic and autotrophic conditions," Bioresource technology, vol. 157, pp. 293-304, 2014. 